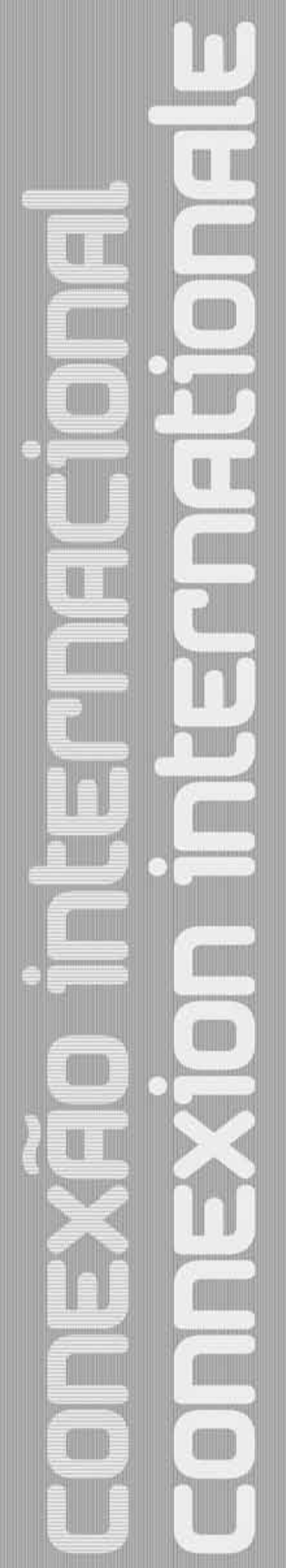





\section{La Pregunta Fundamental. Elementos de la semiótica peirciana para la Investigación en arte}

Roberto Fajardo*

RESUMO: O texto explora maneiras de inferir através da lógica e sua relação com a prática daquilo que entendemos como "arte", a partir da proposta de Peirce que considera a abdução como a lógica do raciocínio sintético; em um processo contínuo e dialético com a teoria Kantiana. Com este exercício buscamos verificar a estrutura fundamental dos silogismos em questão e estabelecer critérios que permitam compreender a lógica do processo criador e fundamentá-lo considerando os processos próprios da criação artística.

PALAVRAS-CHAVE: lógica, abdução, arte

ABSTRACT: The text explores the types of inferences accepted by logic and their relation with the practice of what we call art. Through Peirce's proposal of abduction as the logic of synthetic reasoning and on a continuous dialectic with Kant, the fundamental structure of the syllogisms in question is verified and an attempt is made to determine a criterion that allows the logical understanding of the creative process and provides a basis for the practice of art from this perspective.

KEYWORDS: logic, abduction, art

\footnotetext{
*Roberto Fajardo é panameño.Realiza sus estudios Universitarios en Brasil, Licenciatura en Pintura (1985), Dibujo (1986), Postgrado en Historia del Arte (1990) Maestría (1994), Especialización en Docencia Superior, Universidad de Panamá (1997) y Doctorado en Artes Visuales (2005). Fajardo-González inicia aquí su carrera profesional, habiendo merecido varios premios en diversos certámenes de Arte. Ha desarrollado una labor docente en varias universidades y centros de arte. Ha realizado exposiciones entre individuales y colectivas en Panamá, Brasil, Nueva York, Washington y Moscú. Actualmente es profesor catedrático de la Universidad de Panamá y actual Vicedecano de la Facultad de Bellas Artes.
} 
El debido abordaje de la investigación en el campo de las artes viene dado por la necesaria aproximación a la propia naturaleza del arte, un asunto siempre espinoso. El arte como actividad y proceso ha tenido un desenvolvimiento permanente y paralelo al desarrollo del conocimiento por inferencias. No necesariamente le es opuesto u hostil, muchas veces se entrecruzan y se retroalimentan.

Sin embargo, tal abordaje o definición debe ser propuesta desde el mundo de las inferencias o al menos comunicada y expuesta en términos del desarrollo del conocimiento teórico y sistemático que permite el establecimiento de los paradigmas en la actualidad disciplinaria.

Una de las primeras tareas al respecto es considerar los modos de inferencias y su relación con la práctica de esto que llamamos arte.

Como señala Peirce, el fundamento del conocimiento debe buscarse, según Kant, en los "juicios sintéticos a priori". También nos parece evidente que este aspecto resulte fundamental para el desarrollo de su semiótica, en la medida en que Peirce propone la abducción como la lógica del razonamiento sintético.

Según Kant, la pregunta central de la filosofía es ¿cómo son posibles los juicios sintéticos a priori? Pero antes de esto viene la pregunta sobre cómo son posibles los juicios sintéticos en general, e, incluso más generalmente, sobre como el razonamiento sintético es de alguna manera posible. Al obtener respuesta al problema general, será comparativamente sencillo contestar el problema particular. Éste es el candado de la puerta de la filosofía. (OFR, Houser/ Kloesel. Tomo I. 2012, p. 123)

Diría que tal asunto no atañe solo a la filosofía sino también al arte, dado que en el arte se ejerce una lógica de la abducción.

Sin embargo, cómo puede entenderse esto en el ámbito de la creación artística?

Tal como lo hemos establecido en un texto precedente ${ }^{2}$ para efectos de nuestro tema de discusión, debemos partir de algunos presupuestos fundamentales, veamos:

1. En términos académicos, el primer desafío es ubicar la práctica artística en el contexto de la discusión generada por el así denominado "giro semiótico" provocada por el desarrollo y devenir de la lingüística de Saussure, el consecuente estructuralismo continental, y el desarrollo de la semiótica peirciana. Esto, en la medida en que consideramos 
que la evolución del arte contemporáneo pasa por los presupuestos desarrollados por "el lenguaje" como objeto cognoscitivo. Se trata de determinar la naturaleza semiótica de su hacer.

2. Que, el artista contemporáneo y en especial el artista adjunto al sistema universitario, se ve impelido a desarrollar un campo de conocimiento que sin ser contrario a lo que hace como arte, sí es necesariamente y parcialmente "extraño" a la intimidad de su operación poética.

3. Esto es, que la práctica artística, como tal, no necesita justificarse como conocimiento sistemático y lógico. A no ser, dentro de una determinada condición cognitiva; en cuanto comunicada, en el ámbito de la terceridad, sobre un contexto particularmente cognoscitivo o epistemológico y, dentro de nuestra esfera de atención; la específicamente referida a "investigación". Lo que de modo alguno opone la naturaleza del arte al conocimiento sistemático ya que consideramos el lenguaje como un proceso en continuo desarrollo.

No debe entenderse aquí, una oposición entre la verdad de lo establecido por el lenguaje y la verdad de lo que la obra establece, pues, reiteramos, debemos dejar claro que el dilema central consiste en una cuestión de grado o tal vez de evolución, el lenguaje es un proceso en desarrollo cuya naturaleza es incorporar aquello que a él es siempre extraño, su "posibilidad de la posibilidad".

4. Debo mantener un criterio ya adoptado que proviene de la "Teoría de la Formatividad" de Luigi Pareyson, en especial su distinción entre Poética (carácter programático y operativo, relativo al hacer, al acto) y Estética (carácter filosófico y especulativo, relativo a la teoría y al pensamiento), como criterios metodológicos para la aproximación a la obra de arte. "La distinción entre estética y poética es particularmente importante y representa, entre otras cosas, una precaución metodológica cuya negligencia conduce a resultados lamentables" (PAREYSON, 1984, p. 24)

Esta distinción resulta metodológicamente fundamental, por cuanto nos permite colocar el foco de atención sobre el proceso creativo (Como eclosión) en contraste con el abordaje conceptual y teórico del mismo. 


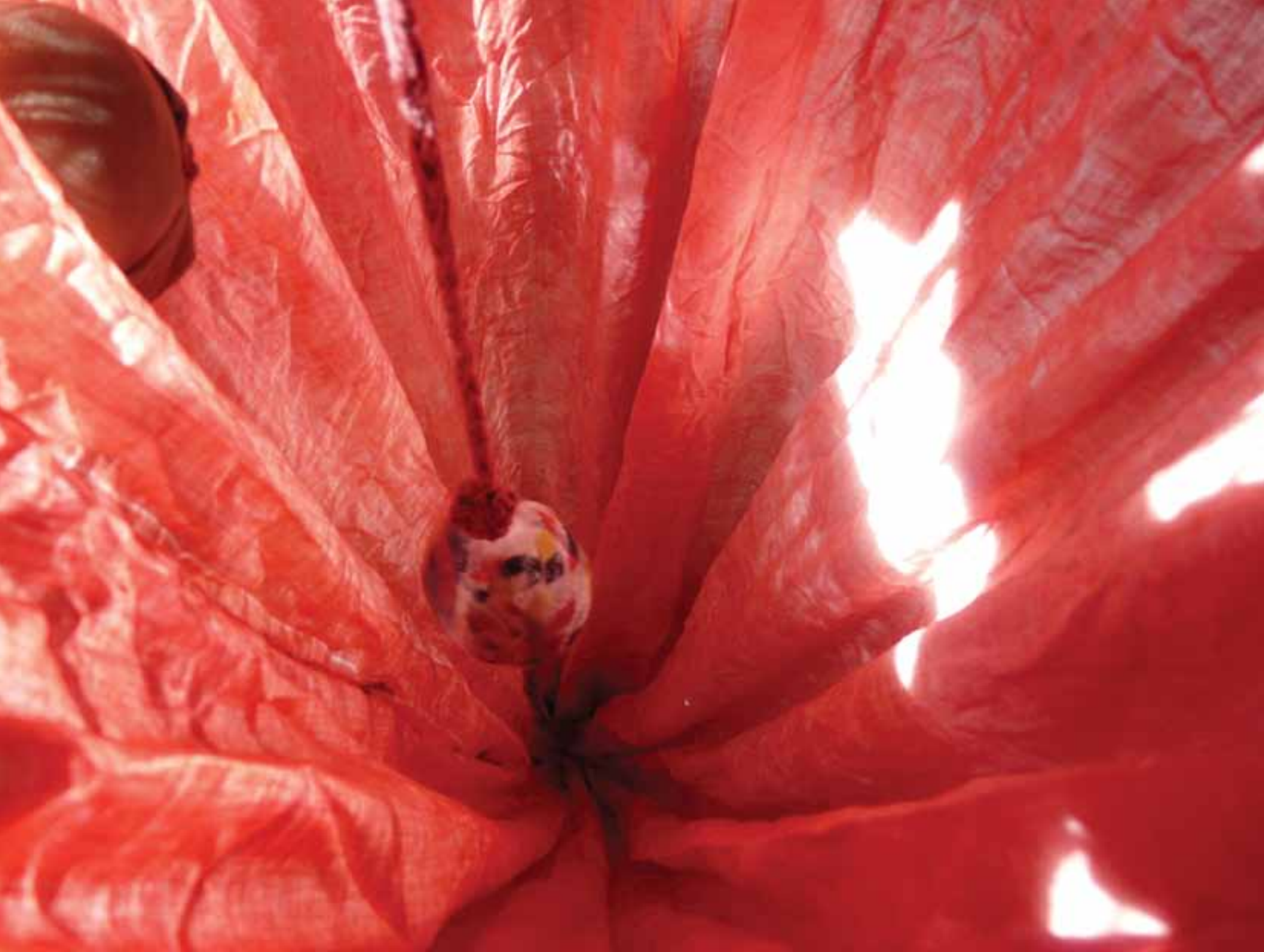

\section{Josiane Bornéo}

Detalle de Secretocaso.

Instalación. 2.20×200×50cm. 2005 


\section{La cuestión cognitiva-conceptual}

Los conceptos son fundamentales, tanto para la comunicación como la generación y comprensión de lo que entendemos por conocimiento. Entendemos que los conceptos reducen a una unidad, la multiplicidad de estímulos que podemos acceder por nuestros sentidos y sensaciones, de modo que podamos condensar determinadas concepciones a través de los mismos. En este sentido, los conceptos se hacen universales en la medida en que así los podemos concebir en su unidad. Una vez manifestado el concepto, este se realiza a través del uso de los argumentos o las inferencias que como sabemos, refieren a la expresión oral o escrita de un razonamiento.

Aprendemos con el estudio de la lógica que una de las clasificaciones fundamentales para entender los argumentos, se refieren al modelo del silogismo proporcionado por la forma Barbara ${ }^{3}$ cuya estructura fundamental es:

\section{S es $M$; $M$ es $P$ : \\ Por tanto, $\mathrm{S}$ es $\mathrm{P}$.}

Regla: Todas las judías de este saco son blancas.

Caso: Estas judías estaban en este saco.

Resultado: Estas judías son blancas.

Esta forma parece ser base fundamental de todo estudio lógico, sin embargo, Peirce nos aclara: "Con todo, dado que toda inferencia puede reducirse de alguna manera a Barbara, no se sigue que esta sea la forma más apropiada para representar a toda clase de inferencia" (OFR, Houser/Kloesel. Tomo I. 2012, p. 233.)

Evidentemente, hay que referirse a los tipos de inferencias y sus relaciones con la variedad de estímulos que somos capaces de experimentar. Si de un lado está la noción de ratio como elemento unitario, por otro lado está la sensación, como origen de toda experiencia y elemento múltiple.

Peirce nos dice que "el concepto universal más cercano a la sensación es aquel de lo presente en general" y agrega "Este concepto de lo presente en general, o del ELLO (IT) en general, se expresa en el lenguaje filosófico por la palabra sustancia en uno de sus significados. (Ídem, p. 
43). La sustancia resulta ser aquello que conecta la realidad del silogismo con la realidad del mundo percibido.

Es por esta razón que Peirce nos dice que una inferencia puede ser deductiva-analítica y sintética. Siendo que la sintética puede dividirse en inducción e hipótesis o abducción. Como sabemos la deducción implica en la aplicación de una regla general a un caso particular. Esta aplicación tiene una condición necesaria: "sólo a condición de que el "es" (del modelo Barbara) signifique: es para los propósitos del argumento" (ídem, p.233), a continuación Peirce nos dice que: "el razonamiento inductivo o sintético, siendo algo más que la mera aplicación de una regla general a un caso particular, no puede nunca reducirse a esta forma" -Barbara- (ídem, p. 234). En el caso de la deducción, la aplicación de la regla sobre un caso y su consecuente resultado está de alguna manera definida de antemano.

Esto nos indica que la condición ideal de la deducción exige un contexto ideal y dado que la experiencia como tal no se sujeta a lo "ideal" resultó necesario para el conocimiento occidental desarrollar fórmulas que pudieran considerar esta condición. Es decir, que fuese capaz de incorporar la realidad de la experiencia desde la experiencia. De aquí, la importancia de la inducción. Pues esta forma supone el caso, su resultado y de allí deduce la regla. Peirce nos dice que la inducción es una inversión de los componentes de la deducción. Resulta interesante observar que Peirce considera que las inversiones de los componentes pre establecidos de la deducción producen la inducción y la hipótesis, como si fuera un ejercicio necesario para romper la condición ideal establecida por la deducción. La inducción al partir de una situación concreta y verificar un resultado; establece su regla.

S es $M$; S es $P$ :

Por tanto: $\mathrm{M}$ es $\mathrm{P}$.

Caso: Estas judías estaban en este saco.

Resultado: Estas Judías son blancas.

Regla: Todas las judías de este saco son blancas.

Recordaremos que para Kant el "a priori" es independiente de la experiencia y lo "sintético", es contingente y en este sentido es extensivo, amplía el conocimiento. Diríamos que en el 
hacer del arte, lo que es distinto a la experiencia es la intencionalidad de generar algo que no está presente con anterioridad, en el arte se parte de un "a priori" que solo es posible como juicio sintético abductivo, y que a pesar de que el arte no sea una actividad que se rige a partir de la construcción de argumentos deductivos, no por esto es incapaz de generar conocimiento. No es que no haya deducción en los proceso artísticos, simplemente no es su paradigma fundamental.

Si bien se asocia la creación artística con la creación libre y la independencia de los procesos lógicos, por otra parte, es necesario observar que el arte también se construye sobre un conocimiento en gran parte establecido teórica y conceptualmente por procesos deductivos e inductivos. Véase por ejemplo, que el estudio de las artes visuales requiere de un dominio concreto y específico sobre conceptos y construcciones teóricas fundamentales para el desarrollo del futuro artista. No se puede pensar en el dominio de la pintura sin un conocimiento profundo de la teoría del color, o la expresión anatómica sin el estudio de la anatomía, o la representación de la perspectiva sin el estudio de la geometría y sus fundamentos teóricos. Mucho menos el ejercicio del arte contemporáneo sin un conocimiento de la historia reciente del arte y del devenir histórico de conceptos como modernidad y posmodernidad.

Ernest H. Gombrich en su ya clásica obra; "Arte e llusión" deja entrever esta realidad. Nos argumenta de manera brillante la idea de que en la pintura se expresa no lo que se ve y si lo que se sabe. El Arte se fundamenta sobre un conocimiento establecido y transmitido, requiriendo de un determinado tipo de abordaje inferencial. Al respecto, Gombrich citándose en conjunto con su amigo Ernst Kris, manifiesta:

Hace tiempo que hemos llegado a darnos cuenta de que el arte no se produce en un espacio vacío, que ningún artista es independiente de predecesores y modelos, que él, no menos que el científico y el filósofo, es parte de una tradición específica y trabaja en una estructurada zona de problemas. El grado de maestría dentro de este marco y, al menos en ciertos períodos, la libertad de modificar estas exigencias, es de presumir que formen parte de la compleja escala por la que se mide el logro. (GOMBRICH, 2009, p. 25) ${ }^{4}$

Sin embargo su específico carácter de arte no es dado por este elemental y necesario dominio y sí por algo más, que le determina. 


\section{Investigación, arte y abducción}

Vale la pena detenernos un poco y observar que el concepto de investigación imperante en gran parte del siglo XX es el resultado de una tradición que remonta en un primer momento al empirismo y en un segundo momento al positivismo y que termina por establecer una relación unívoca entre el método científico y lo que se entiende por investigación. De tal modo que en algunos contextos de producción de conocimiento, el método científico es la base de toda investigación.

La investigación científica supone la observación objetiva de un fenómeno desde el establecimiento de mecanismos que garanticen que los resultados puedan ser reproducidos, sean verificables y entendidos según una regla general y sobre todo, que se puedan aplicar. El método supone una validación rigurosa que le sustente y de este se derivan aquellos modelos que sustentan el nacimiento de las llamadas Ciencias Sociales.

Hay quienes incluyen el arte en el panorama de las Ciencias Sociales pero el arte no es una Ciencia Social y la aplicación de estos métodos aquí, presenta graves escollos. El método científico se fundamenta en la separación del "sujeto" que investiga y el objeto, "objeto" del estudio; resulta necesario un distanciamiento ante el objeto que se observa y la adopción de un determinado modo de abordarlo. Este determinado modo de abordarlo supone una capacidad de reproducirlo como si se tratara de un fenómeno natural, todavía, verificarlo bajo un determinado paradigma idóneo para definirlo de tal modo que se pueda aplicar a otras situaciones similares o no.

De acuerdo con Peirce, el proceso inferencial es dinámico. No hay un concepto que pueda existir fuera de la Semiosis y es de su naturaleza reflejar diversos aspectos, de modo que en el tiempo sea el constante devenir, el que fija su naturaleza. El concepto como tal es una virtualidad, un nexo con el incontenible mundo de la experiencia.

Esta teoría da lugar a una concepción de gradación entre aquellos conceptos que son universales. Pues un concepto tal puede unir la diversidad de la sensación y, sin embargo, puede requerirse otro para unir el concepto y la diversidad a la que se aplica; y así sucesivamente. (OFR, Houser/Kloesel. Tomo I. 2012, p. 43) 
y la variedad pura, lo inmediato y lo original. La Segundidad es la categoría de la interacción. De la causa y el efecto, de la acción y la reacción. Y la Terceridad, es la categoría del orden y el consenso, el acuerdo y la ley, de la mediación.

En estos términos la abducción refiere a la Primeridad.

La abducción es una forma de razonamiento cuyo resultado es una hipótesis y esto es contrario a los postulados de la inferencia lógica válida. En el caso de la hipótesis como conclusión, ésta afirma más de lo que puede inferirse de las premisas, con esto Peirce termina por comprender que la racionalidad refiere a mucho más que solamente los postulados de la inferencia lógica válida.

El concepto de abducción no era nuevo para Peirce, lo habría encontrado ya en Aristóteles (Primeros Analíticos) bajo el nombre de Apagogé y sería el resultado de invertir los términos de un silogismo deductivo. Es la inferencia de un caso a partir de una regla y un resultado. Veamos:

\author{
M es P: S es P; \\ Por tanto, $\mathrm{S}$ es $\mathrm{M}$.
}

Regla: Todas las judías de este saco son blancas.

Resultado: Estas judías son blancas.

Caso: Estas judías provienen de este saco.

El concepto y el tipo de silogismo que representa la abducción, tienen la virtud de insertar en las operaciones de la lógica aquello que es indeterminación, aquello, precisamente, que está fuera de la lógica. Esta paradoja solo puede entenderse si concebimos los procesos lógicos como estructuras construidas que al mismo tiempo que explican el mundo tienen que someterlo, entendiendo que no pueden, abrazarlo completamente. El fin de la lógica es el seguir la huella que puede explicar y dar sentido a ese mundo que se presenta como multiplicidad y que podemos experimentar de muchos modos. Hay algo de "investigare" en toda propuesta de racionalidad.

La palabra investigación en su raíz etimológica implica en examinar, observar y descubrir, la palabra se deriva del latín "investigare" que se refiere a "seguir la huella o la pista", busca 


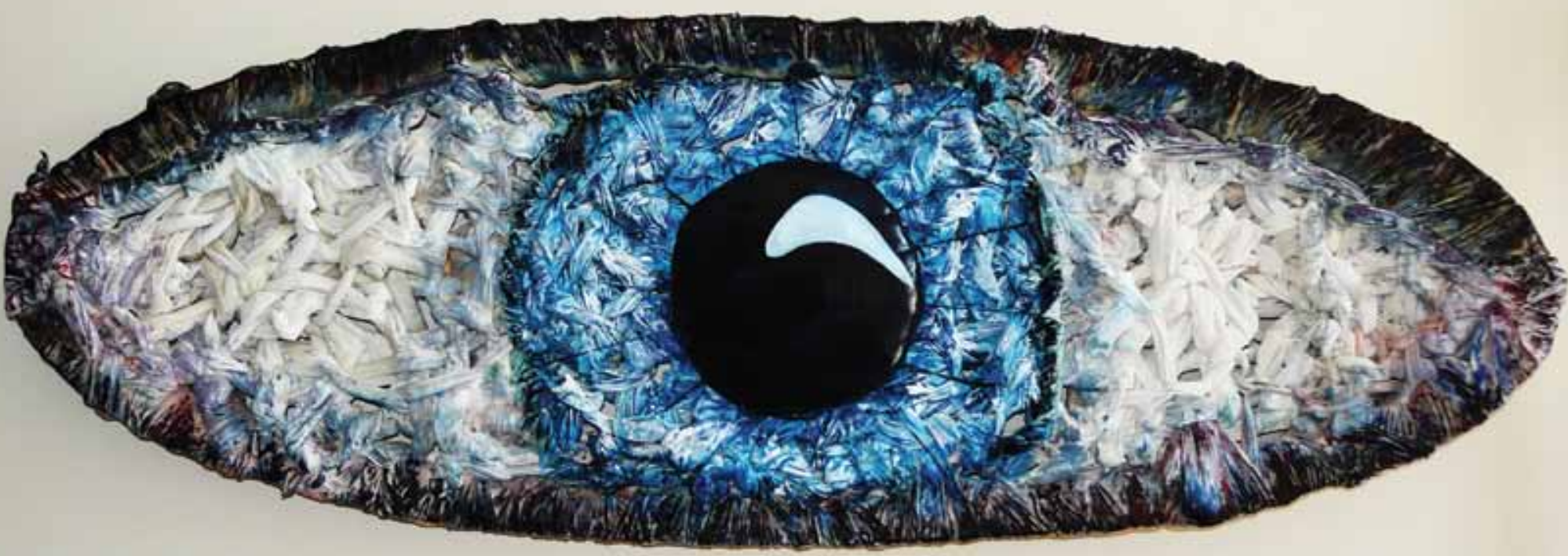

Josiane Bornéo

¡OJO! Estructura en madera, tela, acrílicas y resina. $65 \times 175$ cms. 2012.

descubrir y en este sentido se relaciona con "vestigium" que remite a "señal visible de algo que ya no está", huella, rastro. Es una acción que sigue una huella para determinar un hecho. (GÓMEZ DE SILVA, 2013,p. 387 y 718)

Si consideramos las manifestaciones tempranas del arte en la pre historia podemos ver que el arte trata de ser una señal visible de lo que no está y de este modo trata de captar lo esencial para la sobrevivencia, trata de entender o "capturar" el mundo que se avalancha como experiencia sobre el individuo, de significarle, de darle sentido. No se trata de un ejercicio solo espiritual o cultural y sí de algo eminentemente práctico, capaz de orientar, unificar y abrir perspectivas concretas. Desde entonces el Arte hace posible la experiencia como fin y sentido de acuerdo con los contextos históricos y culturales.

Desde el arte, tal "Investigare" refiere al acto de apostar a lo posible, como resultado de un proceso y el manejo de los presupuestos del lenguaje artístico escogido y la amplia variedad de la materia prima del mundo como experiencia y evidentemente de las particularidades del autor y su contexto. El propio hacer del arte es respuesta y propone una visión de mundo, un 
sentido construido como un todo, que de alguna manera refleja esa unidad que debe viabilizar la multiplicidad de las emociones que recibimos en un todo único: la obra.

En cuanto Arte, estamos hablando de un estadio pre-lenguaje, anterior a la instauración de los procesos lógicos y sistemáticos que caracterizan a nuestra fuente cognitiva occidental; el mundo griego. Hablamos de una acción, actitud o signo que debe apostar en lo que es posible a partir de un camino instintivo. Y también estaremos hablando de su desarrollo histórico y epistemológico y la consecuente acumulación de materia prima que viene de todo lo que es deducción e inducción.

Desde entonces, hay una historia de la "posibilidad de la posibilidad" desde lo que en algún momento llamaremos "arte" y que termina por ajustarse a los diferentes sistemas cognitivos y sistemas científicos desarrollados por nuestra civilización, siendo que en algún momento el arte se vería beneficiado por el surgimiento de un sistema de naturaleza conceptual, el cual procura identificarse con la historia de la razón y la percepción de sensaciones y emociones. Es el nacimiento de la Estética con Baumgarten en 1758.

El Arte se construye sobre la herencia del saber y los efectos de las acciones, sobre las estructuras de la cultura y de todo contexto heurístico. El Arte no se construye sobre un vacío, al contrario no pocas veces el Arte deja en evidencia una compleja capacidad intelectual y técnica, perceptiva y expresiva.

En la tríade peirciana el concepto de signo se puede ver desde dos perspectivas; una referente a la relación entre los elementos de la tríade en la condición de Semiosis, el signo como un todo. Pero, también puede referirse al primer miembro de esa relación, lo que Peirce llamo: Representamen. Aquí tiene un desempeño interesante el concepto de representación; el signo representa el objeto, pero lo hace porque el objeto determina el signo. Sin embargo el signo es un primero y el objeto es un segundo, el objeto solo es accesible por la vía del signo. Esa condición primera, es la primera condición del ejercicio del arte, ejercicio de confecciones sobre las posibilidades de acceder "su objeto". Ejercicio de representaciones.

Pero, el signo no puede representar el objeto en su totalidad, es por esto que es representación. Representación ésta, que estará para un interpretante determinado por el signo como infinita representación mediada, un tercero. La acción del arte denuncia un aspecto ontológico sobre la relación del artista con el mundo, si la ontología generalmente es entendida como la investigación del ser en tanto que es, en el arte, es la investigación del ser en tanto que puede 
ser. Creo que aquí encontramos la base de la producción en arte y el carácter investigativo de su hacer.

El punto es que la estrategia del arte se plantea desde la postura de la "posibilidad de la posibilidad". Desde el Ser como posibilidad. Sin embargo, esta posibilidad se construye y se dirige a hechos concretos, deductivos e inductivos. Es determinación de la indeterminación. Determinación esta, que se da como terceridad, por cuanto esta posibilidad del ser generalmente implica toda una tradición del hacer y saber, en términos de técnica y cultura, en términos de filosofía y poética.

Entonces el proceso de Semiosis, como representación, se plantea en el arte como estrategia fundamental.

Es decir, si el proceso de Semiosis en cuanto producción de sentido se dispara al infinito en una eterna reproducción, es de ésta misma naturaleza la disposición del que hace arte. Disposición que es siempre un "disponere" ${ }^{5}$. Tal disposición se hace desde un haber-hacer que tradicionalmente ha quedado fuera de la historia del razonamiento.

Solo la inferencia abductiva permite el análisis de la actividad artística desde este "disponere" del artista y su integración con los otros tipos de inferencias. Solo la inferencia abductiva es capaz de integrar las dimensiones humanas que generalmente la razón subestima y que son determinantes para el proceso creador, tales como:

La imaginación,

La intuición,

La subjetividad,

Lo impredecible,

La sorpresa,

Lo original,

El descubrimiento,

El juego,

Lo lúdico,

La cualidad.

Las cuales se constituyen en estrategias concretas y sustanciales para ese "disponere" propio del arte ${ }^{6}$. 
Desde la perspectiva semiótica de Peirce, todo fenómeno, todo sentido, todo acto, toda percepción, se aborda como signo. Signo en cuanto Semiosis de sus componentes y como representación, al ser este el elemento vehículo de toda semiosis. El Arte trata de esta condición, de aquello que vehicula y de lo que de eso se deriva. Pero no se resta de la Semiosis, donde todas las categorías son actuantes y todos los modos de inferencias son válidos.

Por esto, la observación y el análisis sobre el proceso investigativo no se hace de fuera ni a la distancia, en términos de la semiosis, en la generación del proceso artístico no hay "sujeto" ni "objeto". Hay semiosis. Generación de sentido.

Así, la objetividad en el arte no tiene el mismo sentido que establece el método científico, esta objetividad define su propio objeto. La "objetividad" refiere al empeño de revelar, encontrar, dar a conocer... originar. Y obviamente los mecanismos de control no se constituyen a partir de los perfiles establecidos por el método científico. En cuanto arte, no se trata de reproducir, verificar y entender (si bien todos estos adjetivos podrían valer a sus propósitos) y sí de producir, autenticar y significar.

\section{Las Ciencias Normativas}

Peirce establece tres ciencias normativas que regulan la validación del conocimiento según sus fines, desde una perspectiva inclusive metafísica. Estas son la Lógica, la Ética y la Estética. Para Peirce la naturaleza humana se dirige al crecimiento y a la evolución que tienden a una perfección, no en su pureza directamente accesible, pero manifestada y en cuanto fin, posible.

La lógica es el estudio del razonamiento correcto, pero este estudio no puede establecer la validad del fin de este razonamiento, esta validación sería una tarea para la ética que se preocupa por orientar este fin. Sin embargo, solo la estética puede establecer cuál es el fin supremo, aquel que tanto la lógica como la ética deben atender como finalidad superior. Para Peirce este fin supremo debe ser algo admirable y deseablepor sí mismo, y que es independiente de cualquier circunstancia o situación.

La búsqueda de lo admirable y deseablepor sí mismo expresa ese "disponere" del artista. Expresa su estrategia fundamental. El arte como ejercicio creativo y generativo continua en la búsqueda de aquello que es "esencial" y que no se identifica en la posmodernidad como 

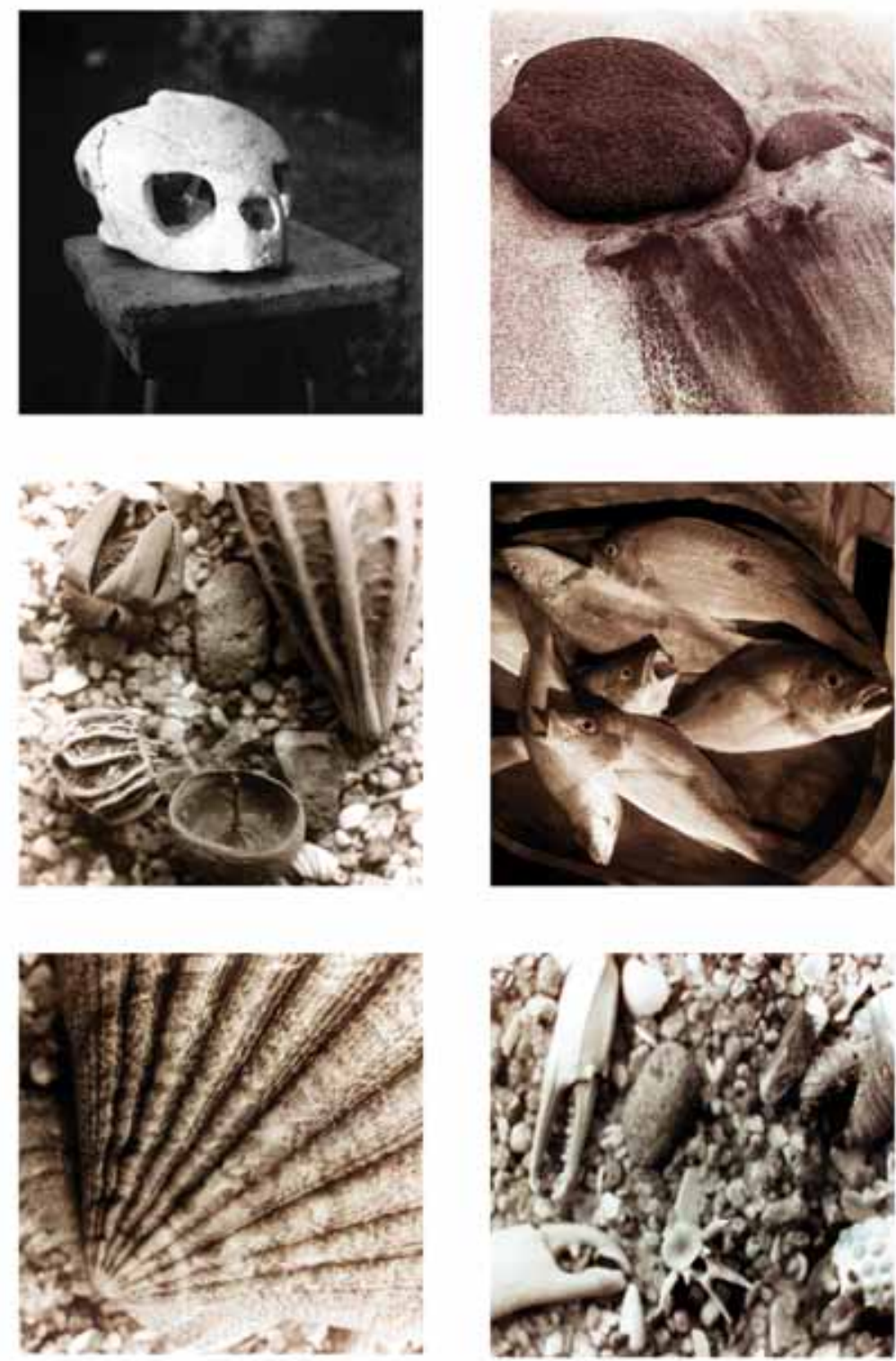
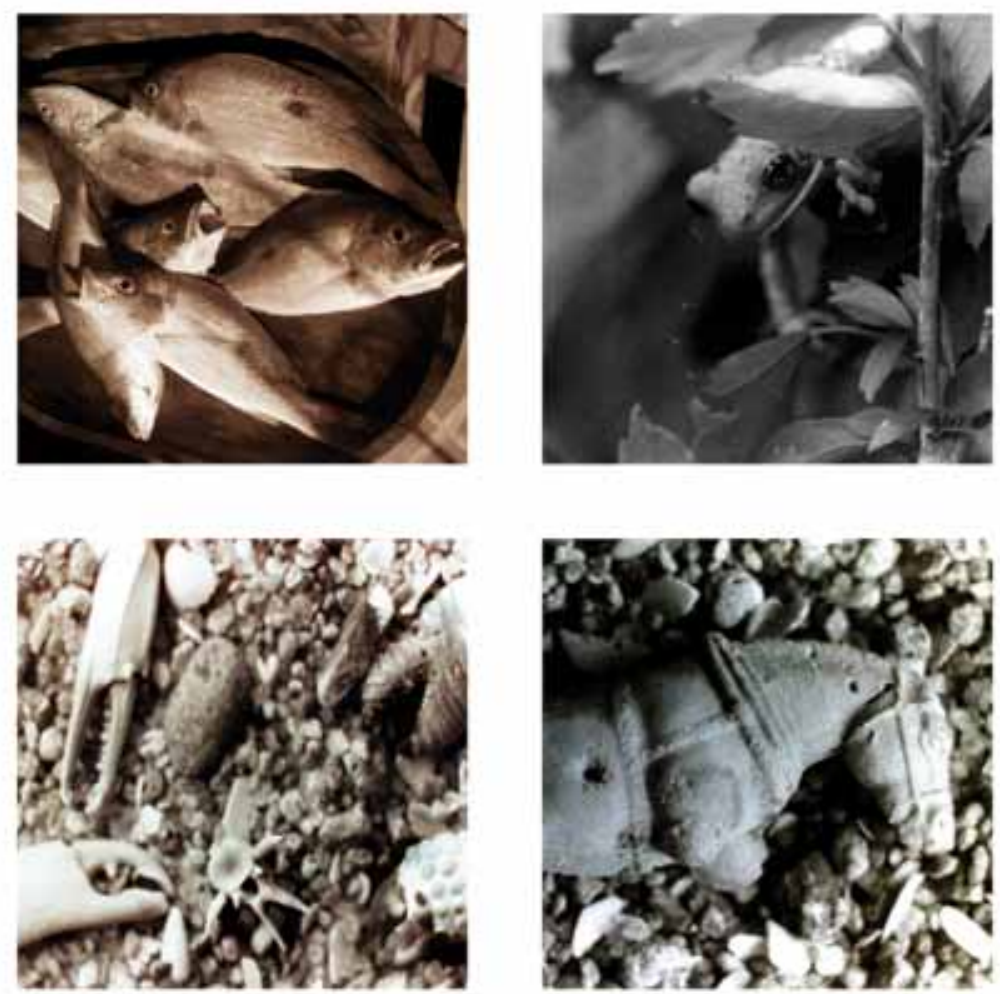

Rafael Martin

Capitulo, fotografía-2014 
"sobrevivencia" pero que al fin del término es también eso. Es ese instinto esencial aplicándose sobre lo que somos en términos de cultura y civilización. Sobre nosotros en contexto y desde ese contexto.

\section{La pregunta fundamental}

La pregunta fundamental no escapa a lo anteriormente expuesto, el establecimiento de los perfiles de investigación para las artes, al menos, sobre el aspecto generativo, creativo o abductivo debe fundamentarse necesariamente sobre la "semiosis" como método y proceso capaz de revelar la multidimensionalidad del hacer del arte y su carácter ontológico (la investigación del ser en cuanto puede ser), aspectos esenciales a su naturaleza. La abducción desde la perspectiva lógica no es una inferencia necesaria y sí contingente, por esto, termina siendo base de todo razonamiento, base de nuestro proceder en la vida cotidiana, base de la operación semiótica, pues debemos siempre proponer o recibir una representación como primer elemento(el signo) inicio de la operación semiótica. Que en Peirce tiene como fin lo "admirable"

En Arte todo proceder se inicia por la búsqueda de lo "admirable" que evidentemente termina siendo una huella en el complejo mundo de la inducción y la deducción. La pregunta fundamental es, entonces:

¿Qué es lo "admirable", como proceso semiótico, para la obra y para el artista?

\section{Notas}

1 En este texto, pasamos a utilizar por primera vez, la traducción al español de Darin McNabb (revisión de Sara Barrena y Fausto José Trejo) de los escritos de Peirce con edición de Nathan Houser y Christian Kloesel con el título original: "The Essential Peirce. Selected Philosophical Writings". Volumen I y II. Traducidos al Español con el título: "Obra Filosófica Reunida" y que será citada en este trabajo bajo las siglas OFR. Publicados por el Fondo de Cultura Económica. México. 2012.

2 La investigación en el campo de las Artes Visuales y el ámbito académico universitario. Publicado por primera vez en el GEP de la Universidad de Navarra. 2010. http://www.unav.es/gep/ArticulosOnLineEspanol.html

3 Barbara es un nombre mnemónico para identificar un tipo de silogismo entre otros, como por ejemplo, Celarent, Darii, Ferio y Darapti. Estos pertenecen a los famosos versos mnemotécnicos sobre la reducción de los silogismos a los modos de la primera figura aristotélica confeccionados por Guillermo de Shyreswood (1210-1267).

4 En la referida obra, Gombrich desarrolla un trabajo depurado sobre la creación de imágenes desde una perspectiva, manifestada por él, psicológica y desde la teoría de la percepción. Resulta interesante destacar que en la sexta edición del año 2000, Gombrich introduce 
un prefacio titulado "Imágenes y Signos", donde expresa: “Todas las imágenes son signos, y la disciplina que debe investigarlos no es la psicología de la percepción-como yo afirmaba-, sino la semiótica, la ciencia de los signos" (GOMBRICH, 2009. Prefacio p. XV)

5 Latín, Disponere: “colocar separadamente". Dis-poner. Poner: colocar, situar, depositar, ocultarse, (alejarse de...). (GÓMESZ DE SILVA, 2013. p. 229 y 553)

6 Al respecto véase el texto de Sara F. Barrena. "La Creatividad en Charles Sanders Peirce" en la Revista Anthropos No. 212. p. $112-120$.

Josiane Bornéo. Artista y educadora oriunda de Brasil, posee una formación básica en Pedagogía, una Licenciatura y una Maestría en Artes Visuales por la Universidad Federal de Río Grande del Sur, Brasil. Artista multifacética, se destaca por sus trabajos de arte contemporáneo. Con una gran experiencia en el campo de la educación del arte, ha sido profesora en Escuelas y Universidades Brasileñas y en la Universidad de Panamá. Curadora del Museo de Arte Contemporáneo de Panamá. Actualmente es profesora de la Maestría en Artes Visuales de la Universidad de Panamá; Fue seleccionada en la IV Bienal de Arte de Panamá. Diversas exposiciones colectivas e individuales entre Brasil y Panamá.

Rafael Martin. Panameño nacido en Londres, 1959. Posee una Licenciatura en Artes con estudios en Rhode Island School or Design 1978-1980 (Dibujo, Pintura, Litografía, grabado, Historia del Arte), en Florida State University 1980 - 1983 (Litografía, serigrafía, Historia del Arte, Fotografía) y en el F.S.U. Stydy Center. Florencia Italia 1983 (Italiano, Historia del Arte, Pintura) Bachelor of Arts in Art. Diversas exposiciones entre USA y Panamá. Trabaja en la Universidad de Panamá y se ha dedicado al grabado, fotografía y artes gráficas. Actualmente finaliza una Maestría en Artes Visuales por la Universidad de Panamá.

\section{Referências}

BARRENA, Sara. La Creatividad en Charles Sanders Peirce. Revista AnthroposNo. 212. Barcelona: Editorial Anthropos. 2012. Págs.112-120.

GOMBRICH, Ernst. H. Arte e llusión. London: Phaidon. 2002.

GÓMEZ DE SILVA, Guido. Breve Diccionario Etimológico de la Lengua Española.

México: Fondo de Cultura Económica. 2013.

PAREYSON, Luigi. Os Problemas da Estética. São Paulo: MartinFontes.1984.

PEIRCE, Charles S. Obra Filosófica Reunida.Tomo I. Nathan Houser y CristianKloesel, editores. México, Fondo de Cultura Económica, 2012.

SANTAELLA, Lucia. Matrizes da linguagem e pensamento. São Paulo:Iluminuras, 2001. 